\title{
Synthesis and characterization of polythiophene with liquid crystalline azobenzene as side chains
}

\author{
Seyed Hossein Hosseini ${ }^{1 *}$, Masoomeh Shirazi Madani ${ }^{2}$, and Seyed Mahdi Musavi ${ }^{3}$
}

\author{
${ }^{1}$ Department of Chemistry, Faculty of Science, Islamic Azad University, Islamshahr branch, Tehran-Iran \\ ${ }^{2}$ Department of Chemistry, Faculty of Science and Engineering, Islamic Azad University, Saveh branch, Saveh- \\ Iran \\ ${ }^{3}$ Departmant of chemistry, faculty of science, Islamic Azad University, Shahr-e-Ray Branch, Tehran, Iran \\ *Corresponding Author: Seyed Hossein Hosseini, Department of Chemistry, Faculty of Science, Islamic Azad \\ University, Islamshahr branch, Tehran-Iran; Email: shhosseini@iiau.ac.ir, Tel./Fax: +98-21-77312543, \\ (+989121374816).
}

\begin{abstract}
In this study a series of azobenzene-functionalized liquid crystalline (LC) polythiophene derivatives:
poly\{2-[N-ethyl- $N$-[4-[4-(nitrophenyl)azo]phenyl] amino]ethyl-3-thiophene acetate\}, Poly(Th3AA-RedI), poly\{2[N-ethyl- $N$-[4-[4-(nitrophenyl)azo]-phenyl]amino]ethyl-3-thiophene acetate-co-thiophene\}, Poly(Th3AA-RedI-coTh), poly\{2-[N-ethyl- $N$-[4-[4-(nitrophenyl)azo]-phenyl]amino]ethyl-3- thiophene acetate-co-pyrrole $\}$, Poly(Th3AA-RedI-co-py) were synthesized. Novel 3-substituted thiophene with liquid crystalline side chain (Th3AA-RedI) was synthesized by the direct reaction of thiophene -3-acetic acid with 2-[N-ethyl- $N$-[4-[4(nitrophenyl)azo]-phenyl]amino]ethanol (RedI). Chemical polymerization of (Th3AA-RedI), and its copolymerization with thiophene and pyrrole were carried out, by using ferric perchlorate as oxidation agent. The composition, structure and thermal property of these LC polythiophene derivatives were fully characterized by FTIR, ${ }^{1} \mathrm{H},{ }^{13} \mathrm{C}-\mathrm{NMR}$ and UV-Visible spectroscopic methods, and its LC behavior and photoresponsive property were also investigated by polarized optical microscope and differential scanning calorimeter (DSC). The results show that Poly(Th3AA-RedI) exhibited the smecticC $\left(\mathrm{S}_{\mathrm{C}}\right)$ and nematic $(\mathrm{N})$ liquid crystalline behavior. Conclusion shifted phase transition temperatures of the poly(Th3AA-RedI) in the heating process are as follows: $\mathrm{C} \rightarrow \mathrm{S}_{\mathrm{c}}\left(108^{\circ} \mathrm{C}\right)$, $\mathrm{S}_{\mathrm{c}} \rightarrow \mathrm{N}\left(200^{\circ} \mathrm{C}\right)$ and $\mathrm{N} \rightarrow \mathrm{I}\left(261^{\circ} \mathrm{C}\right)$. Electrical conductivity of polymer [poly(Th3AA-RedI)] and of two its copolymers [poly(Th3AA-RedI-co-Th) and poly(Th3AA-RedI-co-Py)], has been studied by four probe methods and produced $3.6 \times 10^{-6}, 4.9 \times 10^{-3}$, and $7.5 \times 10^{-3} \mathrm{Scm}^{-1}$ conductivities, respectively.

[Seyed Hossein Hosseini, Masoomeh Shirazi Madani, and Seyed Mahdi Musavi. Synthesis and characterization of polythiophene with liquid crystalline azobenzene as side chains. Life Sci J 2012;9(4):5050-5064]. (ISSN: 1097-8135). http://www.lifesciencesite.com. 755

Key word: Liquid crystalline polymers, Polythiophene, Conducting polymers, optical materials, Electrical conductivity
\end{abstract}




\section{Introduction}

Conjugated polymers are well-known for their excellent electrical conductivities in oxidized (doped) state. The recent development of processable conducting polymers has opened the way for large-scale industrial applications. Conjugated polymers have been used widely in many areas such as rechargeable batteries $[1,2]$, electrochromic devices [3], diodes and sensors [4-6]. Among these classes of polymers, polyaniline, polypyrrole, polythiophene, etc. have been studied extensively because of their favorable processibility and relative stability [7-9]. Polythiophene derivatives have been used widely as conducting materials. In comparison with other conjugated polymers, polythiophenes are relatively easy to be functionalized, and the attachment of substituted through $\beta$-carbons has relatively little impact on electronic properties of the conjugated backbone. Therefore, synthesis of three-substituted azobenzene-functionalized polythiophenes has attracted much interest both from synthetic considerations as well as from material science. polythiophenes with azobenzene groups in three-position will not only have better processibility and stability, but also may possess novel electrical, electrochemical and optical properties. Thus, the combination of polythiophene backbone with photoactive azobenzene groups can provide a new approach to develop other novel materials with unique electronic and optical properties [10]. Various type of liquid crystalline (LC) conjugated polymers have been currently synthesized to cultivate fruitful molecular electronics. Polythiophene derivative with LC side chain is one of the most intriguing polymers, because its profound electrical and optical properties are expected to be controlled using molecular orientation of LC side chain $[11,12]$. In the previous works, we reported liquid crystalline polymer based N-substituted pyrrol [13]. This polymer exhibit liquid crystalline and electrically conductivity properties, as well. In this paper, polythiophene was selected as main chain skeleton. The side chain polythiophene contains mesogenic group which shows liquid crystalline property. The 3 -substituted of the thiophene ring was prepared and their liquid crystalline and thermal properties investigated. Figure 1 shows side chain polythiophene. So, a series of novel LC azobenzene-functionalized polthiophene synthesized with the aims at preparation of liquid crystalline thiophene derivatives for photonic applications. The synthesis, polythiophene derivatives were fully discussed. Molecular structure of the LC polythiophene is illustrated in Figure 2, where LC group is introduced in to 3-position of the thiophene unite. The polymer consists of main chain, flexible methylene spacer, linking group and tailing group, as shown in Figure 2. 


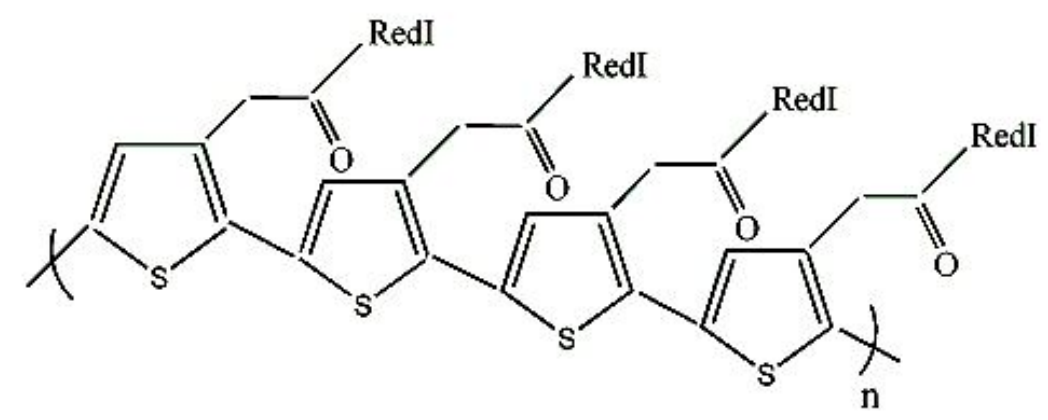

Figure 1: Side chain polythiophene

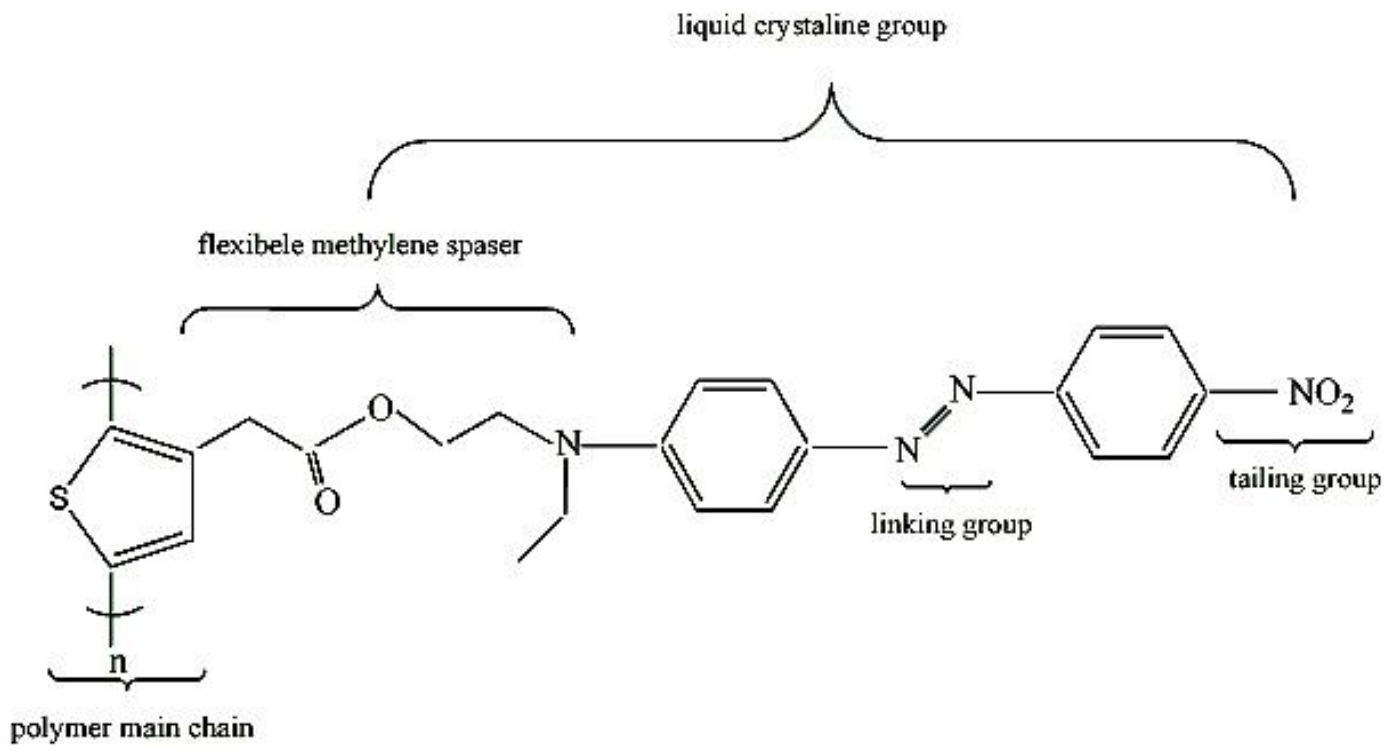

Figure 2: Molecular structure of liquid crystalline polythiophene derivative

\section{Experimental}

\subsection{Physical measurements}

${ }^{1} \mathrm{H},{ }^{13} \mathrm{C}-\mathrm{NMR}$ spectra were recorded at $250 \mathrm{MHz}$ on a BRUKER, NMR data are reported in the following order: chemical shift (ppm), spin multiplicity $(\mathrm{s}=$ singlet, $\mathrm{d}=$ doublet, $\mathrm{t}=$ triplet, $\mathrm{q}=$ quartet, $\mathrm{m}=$ multiplet), and integration. Electrical conductivity were measured with a four-probe device (home made). Differential Scanning Calorimeter (DSC) analyses were performed at $5{ }^{0} \mathrm{C} \mathrm{min}^{-1}$ on a TA instruments using STA 625 DSC. FTIR spectra were recorded on a 8101-MShimadzu and BRUKER-IF-66.5 spectrometer. Vibration transition frequencies are reported in wave number $\left(\mathrm{cm}^{-1}\right)$. The UVVisible spectra were obtained using an UV-Vis recording spectrophotometer (Perkin-Elmer Lambda 15).

\subsection{Materials}

Thiophene-3-acetic acid (Fluka), thiophene (Merck) and pyrrole (Fluka, 96\%) were distilled prior to use. Tetrahydrofuran (Merck), petroleum ether and ethyl acetate were distilled and dried with molecular sieves $\left(4 \mathrm{~A}^{\circ}\right)$ prior to use. 4-nitroaniline (Merck, 98\%), dicyclohexyl carbodiimide (DCC) (Merck, 98\%), 4(dimethylamino) pyridine (DMAP) (Merck, 99\%), 2-(N-ethyl aniline) ethanol (Merck, $99 \%)$, sodium nitrite $\left(\mathrm{NaNO}_{2}\right)($ Merck, $99 \%)$, methanol (Merck) and the other materials used in this work were purchased from Merck chemicals and purified, or prepared according to literature methods.

2.3. Preparation of $2-[\mathrm{N}$-ethyl- $\mathrm{N}-[4-[\mathbf{( 4}-$ nitrophenyl)azo]-phenyl]amino] ethyl (RedI)

$7 \mathrm{~g}(0.05 \mathrm{~mol})$ of 4-nitroaniline was dissolved in a solution of $25 \mathrm{ml}$ of concentrated hydrochloric acid and $150 \mathrm{ml}$ of water. The mixture was cooled to $0{ }^{0} \mathrm{C}$ in an ice-water bath, then a solution of $3.6 \mathrm{~g}(0.05 \mathrm{~mol})$ of sodium nitrite in $15 \mathrm{ml}$ of water was added dropwise. The resultant solution of neutralized salt was stirred for $30 \mathrm{~min}$ at $0-3{ }^{0} \mathrm{C}$. Another solution of $5 \mathrm{~g}(0.03 \mathrm{~mol})$ of N-ethyl-Nhydroxy ethyl aniline dissolved in $10 \mathrm{ml}$ of 
hydrochloric acid (10\%) was stirred for $5 \mathrm{~min}$ at $0{ }^{0} \mathrm{C}$. The above solution of neutralized salt was added into this solution within $30 \mathrm{~min}$. Allow the mixture to stand for $20 \mathrm{~min}$ and then was neutralized with added slowly and with stirring 10 percent $\mathrm{NaOH}$ solution. Reddish crystals filtered on a Buchner funnel and recrystallized with 2-propanol. Compound 1 was obtained as crimson crystals. Yield 9 g85\%, mp: $170-173^{\circ} \mathrm{C}$. UV (THF): $\lambda_{\max }=470$ $\mathrm{nm}$ (0.95 intensity). FT-IR ( $\mathrm{KBr}$ pellets, $v$ in $\left.\mathrm{cm}^{-1}\right), v: 3434\left(v_{\mathrm{OH}}\right), 3200\left(v_{\mathrm{C}-\mathrm{H}}, \mathrm{Ar}\right), 2950\left(v_{\mathrm{C}-}\right.$ $\mathrm{H}, \mathrm{Al}), 1599\left(\mathrm{v}_{\mathrm{N}=\mathrm{N}}\right), 1515,1341\left(\mathrm{v}_{\mathrm{NO} 2}\right), 1450$ $\left(v_{\mathrm{C}=\mathrm{C}}\right), 1141\left(\mathrm{v}_{\mathrm{C}-\mathrm{O}}\right), 800-850\left(\mathrm{v}_{\mathrm{C}-\mathrm{H}}, \mathrm{OOP}\right) \mathrm{cm}^{-1}$. ${ }^{1} \mathrm{H}-\mathrm{NMR}\left(\mathrm{CDCl}_{3}\right): \delta 1.26(3 \mathrm{H}, \mathrm{t}), 1.75(1 \mathrm{H}, \mathrm{s})$, $3.56(2 \mathrm{H}, \mathrm{q}), 3.62(2 \mathrm{H}, \mathrm{t}), 3.90(2 \mathrm{H}, \mathrm{t}), 6.81$ $(2 \mathrm{H}, \mathrm{d}), 7.88(2 \mathrm{H}, \mathrm{d}), 7.92(4 \mathrm{H}, \mathrm{d}), 8.32(2 \mathrm{H}$, d) $\mathrm{ppm} .{ }^{13} \mathrm{CNMR}\left(\mathrm{CDCl}_{3}\right): \delta 12.1,46.4,52.8$, $60.1,112.3,122.5,124.7,126.6,143.8,147.2$, $151.6,157.2 \mathrm{ppm}$.

\subsection{Preparation of $\{2-[N$-ethyl- $N-[4-[(4-$ nitrophenyl)azo]-phenyl] amino] ethyl-3- thiophene acetate\}, (Th3AA-RedI)}

A total $1 \mathrm{~g}(0.012 \mathrm{~mol})$ of thiophene -3 -acetic acid and $1.884 \mathrm{~g}(0.006 \mathrm{~mol})$ of RedI (crystallized in isopropyl alcohol) were dissolved in $50 \mathrm{ml}$ of dry THF. Then $1.279 \mathrm{~g}$ $(0.0062 \mathrm{~mol})$ of N-N-dicyclohexyl carbodiimide (DCC) and $0.109 \mathrm{~g}(0.9 \mathrm{mmol})$ of 4-(dimethylamino) pyridine (DMAP) were added to the vigorously stirred solution. The stirring was continued for $5 \mathrm{~h}$. The mixture was then filtered, and the solvent was removed by rotary evaporator under vacuum. The product was purified by column chromatography (silica gel, petroleum ether: ethyl acetate $=2: 2, \quad \mathrm{v} / \mathrm{v})$, followed by recrystallized from petroleum ether/ethyl acetate to yield red crystals (Compound 2 was obtained as red crystals). Yield: $55 \%$, UV (THF); $\lambda_{\max }=446 \mathrm{~nm}$ (0.26 intensity), $253 \mathrm{~nm}$ (2.35 intensity), $212 \mathrm{~nm}$ (3.26 intensity). FTIR $\left(\mathrm{KBr}\right.$ pellets, $v$ in $\left.\mathrm{cm}^{-1}\right), \mathrm{v}: 3100\left(\mathrm{v}_{\mathrm{C}-\mathrm{H}}, \mathrm{Ar}\right)$, $2910\left(v_{\mathrm{C}-\mathrm{H}}, \mathrm{Al}\right), 1625\left(v_{\mathrm{C}=\mathrm{O}}\right), 1601\left(v_{\mathrm{N}=\mathrm{N}}\right)$, $1515,1340\left(v_{\mathrm{NO} 2}\right), 1627,1455\left(v_{\mathrm{C}=\mathrm{C}}\right), 1140$ $\left(v_{\mathrm{C}-\mathrm{O}}\right), 859\left(\mathrm{v}_{\mathrm{C}-\mathrm{H}}\right.$, OOP $) \mathrm{cm}^{-1} .{ }^{1} \mathrm{H}-\mathrm{NMR}\left(\mathrm{d}^{6}{ }^{6}\right.$ DMSO): $\delta 1.24(3 \mathrm{H}, \mathrm{t}), 3.47(2 \mathrm{H}, \mathrm{q}), 3.66(2 \mathrm{H}$, t), $3.79(2 \mathrm{H}, \mathrm{s}), 4.33(2 \mathrm{H}, \mathrm{t}), 6.79(2 \mathrm{H}, \mathrm{d}), 7.01$ 7.30 (4H thiophene, m), $7.87(2 \mathrm{H}, \mathrm{d}), 8.33$ (2H, d), ppm. ${ }^{13}$ CNMR (d ${ }^{6}$ - DMSO): $\delta 12.2$, 35.7, 45.5, 48.6, 61.8, 111.4, , 122.6, 123.1, $124.6,126,126.2,128.4,143.8,147.3,151$, 156.7, $171 \mathrm{ppm}$.

2.5. Preparation of Poly $\{2-[N-e t h y l-N-[4-[(4-$ nitrophenyl)azo]-phenyl] amino] ethyl-3thiophene acetate\}, Poly(Th3AA-RedI)

Polymerization was carried out as follows: The $0.5 \mathrm{~g}(0.1 \mathrm{mmol})$ of monomer (Th3AA-RedI) in $25 \mathrm{ml}$ THF was added dropwise to a suspension $0.1062 \mathrm{~g}$, $(0.3 \mathrm{mmol})$ of $\mathrm{Fe}\left(\mathrm{ClO}_{4}\right)_{3}$ in $20 \mathrm{ml}$ of THF under nitrogen atmosphere. The mixture was stirred at $50^{\circ} \mathrm{C}$ temperature for $24 \mathrm{~h}$. The polymerization mixture was added dropwise into $100 \mathrm{ml}$ of methanol. The precipitates were filtrated, dissolved in $5 \mathrm{ml}$ of THF, and reprecipitated into $100 \mathrm{ml}$ of methanol. This procedure was repeated three time until the unreacted monomers were completely removed. Finally, the polymer was dried under vacuum at $25{ }^{\circ} \mathrm{C}$ to constant weight. (Compound 3 was obtained). UV (THF): $\lambda_{\max }=446 \mathrm{~nm}$ (0.25 intensity), $297 \mathrm{~nm}$ (0.54 intensity), $253 \mathrm{~nm}$ (2.74 intensity), 211 $\mathrm{nm}$ (3.94 intensity). FT-IR ( $\mathrm{KBr}$ pellets, $v$ in $\left.\mathrm{cm}^{-1}\right), \mathrm{v}: 3100\left(v_{\mathrm{C}-\mathrm{H}}, \mathrm{Ar}\right), 2929\left(\mathrm{v}_{\mathrm{C}-\mathrm{H}}, \mathrm{Al}\right), 1732$ $\left(v_{\mathrm{C}=\mathrm{O}}\right), 1627\left(v_{\mathrm{N}=\mathrm{N}}\right), 1516,1388\left(v_{\mathrm{NO} 2}\right), 1134$ $\left(v_{\mathrm{C}-\mathrm{O}}\right) \mathrm{cm}^{-1}, 823\left(v_{\mathrm{C}-\mathrm{H}}, \mathrm{OOP}\right) \mathrm{cm}^{-1}$.

${ }^{1} \mathrm{H}-\mathrm{NMR}$ ( $\mathrm{d}^{6}$-DMSO): $\delta 1.25(3 \mathrm{H}, \mathrm{t}), 3.61(2 \mathrm{H}$, q), $3.47(2 \mathrm{H}, \mathrm{q}), 3.67(2 \mathrm{H}, \mathrm{t}), 3.79(2 \mathrm{H}, \mathrm{s}), 4.35$ $(2 \mathrm{H}, \mathrm{t}), 6.80(2 \mathrm{H}, \mathrm{d}), 7.01-7.30$ (4H thiophene, m), 7.87-7.94 (4H, m), 8.31-8.34 (2H,d) ppm. ${ }^{13}$ CNMR (d - DMSO): $\delta 12.2,35.7,45.6,48.7$, $61.8,111.4,122.6,123.1,124.7,125.9,126$, $128.4,143.8,147.4,151.2,156.7,171 \mathrm{ppm}$.

\subsection{Preparation of Poly\{2-[N-ethyl- $N-[4-[(4-$ nitrophenyl)azo]-phenyl] amino ] ethyl-3- thiophene acetate-co- thiophene \}, Poly(Th3AA-RedI-co-Th)}

The typical synthesis procedures utilized can be described as fellows: The $0.1 \mathrm{~g}(0.22 \mathrm{mmol})$ of monomer (Th3AA-RedI) and $0.0092 \mathrm{~g}$ $(0.1 \mathrm{mmol})$ of monomer thiophene in $10 \mathrm{ml}$ of THF was added dropwise to a suspension $0.233 \mathrm{~g}(0.65 \mathrm{mmol})$ of $\mathrm{Fe}\left(\mathrm{ClO}_{4}\right)_{3}$ in $10 \mathrm{ml}$ of THF under nitrogen atmosphere. The mixture was stirred at $50^{\circ} \mathrm{C}$ temperature for $24 \mathrm{~h}$. The copolymer in solution was precipitated by addition of excess methanol. The precipitation was extracted using boiling absolute ethanol. The precipitate was dried under vacuum. FTIR $\left(\mathrm{KBr}\right.$ pellets, $v$ in $\left.\mathrm{cm}^{-1}\right)$, v: $2920\left(v_{\mathrm{C}-\mathrm{H}}, \mathrm{Al}\right)$, $1713\left(v_{\mathrm{C}=\mathrm{O}}\right), 1600\left(v_{\mathrm{N}=\mathrm{N}}\right), 1516,1338\left(\mathrm{v}_{\mathrm{NO} 2}\right)$, $1463\left(v_{\mathrm{C}=\mathrm{C}}\right), 1133\left(\mathrm{v}_{\mathrm{C}-\mathrm{O}}\right) \mathrm{cm}^{-1} .{ }^{1} \mathrm{H}-\mathrm{NMR}\left(\mathrm{d}^{6}{ }^{6}\right.$ DMSO): $\delta 1-1.22$ (broad), 3.38 (broad), 6.78.32 (broad).

\subsection{Preparation of Poly\{2-[N-ethyl- $N-[4-[(4-$ nitrophenyl)azo]-phenyl] amino ] ethyl-3- thiophene acetate-co- pyrrole \}, Poly(Th3AA-RedI-co-Py)}

Poly(Th3AA-RedI-co-Py) was synthesized using the same synthetic procedures as for Poly(Th3AA-RedI-co-Th). The (Th3AA-RedI) monomer $(0.1 \mathrm{~g}, 0.22 \mathrm{mmol})$ and pyrrole $(0.0074 \mathrm{~g}, 0.1 \mathrm{mmol})$ in anhydrous THF (10 $\mathrm{mL}$ ) was added dropwise to a suspension of $\mathrm{Fe}\left(\mathrm{ClO}_{4}\right)_{3}(0.233 \mathrm{~g}, 0.65 \mathrm{mmol})$ in THF (10 
$\mathrm{ml})$ under nitrogen. The mixture was stirred at $50^{\circ} \mathrm{C}$ temperature for $24 \mathrm{~h}$. The polymer in solution was precipitate by addition of excess methanol. The precipitation was extracted using boiling absolute ethanol. The precipitate was dried under vacuum. FT-IR ( $\mathrm{KBr}$ pellets, $v$ in $\left.\mathrm{cm}^{-1}\right), v: 3400\left(v_{\mathrm{N}-\mathrm{H}}, \mathrm{Py}\right), 3181\left(\mathrm{v}_{\mathrm{C}-\mathrm{H}}, \mathrm{Ar}\right)$, $2931\left(v_{\mathrm{C}-\mathrm{H}}, \mathrm{Al}\right), 1699\left(v_{\mathrm{C}=\mathrm{O}}\right), 1600\left(v_{\mathrm{N}=\mathrm{N}}\right)$, $1516,1433\left(v_{\mathrm{NO} 2}\right), 1244\left(v_{\mathrm{C}-\mathrm{O}}\right), 828\left(v_{\mathrm{C}-\mathrm{H}}\right.$, OOP) $\mathrm{cm}^{-1}$.

\section{Results and discussion}

All synthetic routes of RedI, Th3AA-RedI and poly(Th3AA-RedI) showed in Scheme I. Therefore, schematic copolymerization of Th3AA-RedI with thiophene and pyrrole has been shown in Scheme II. 


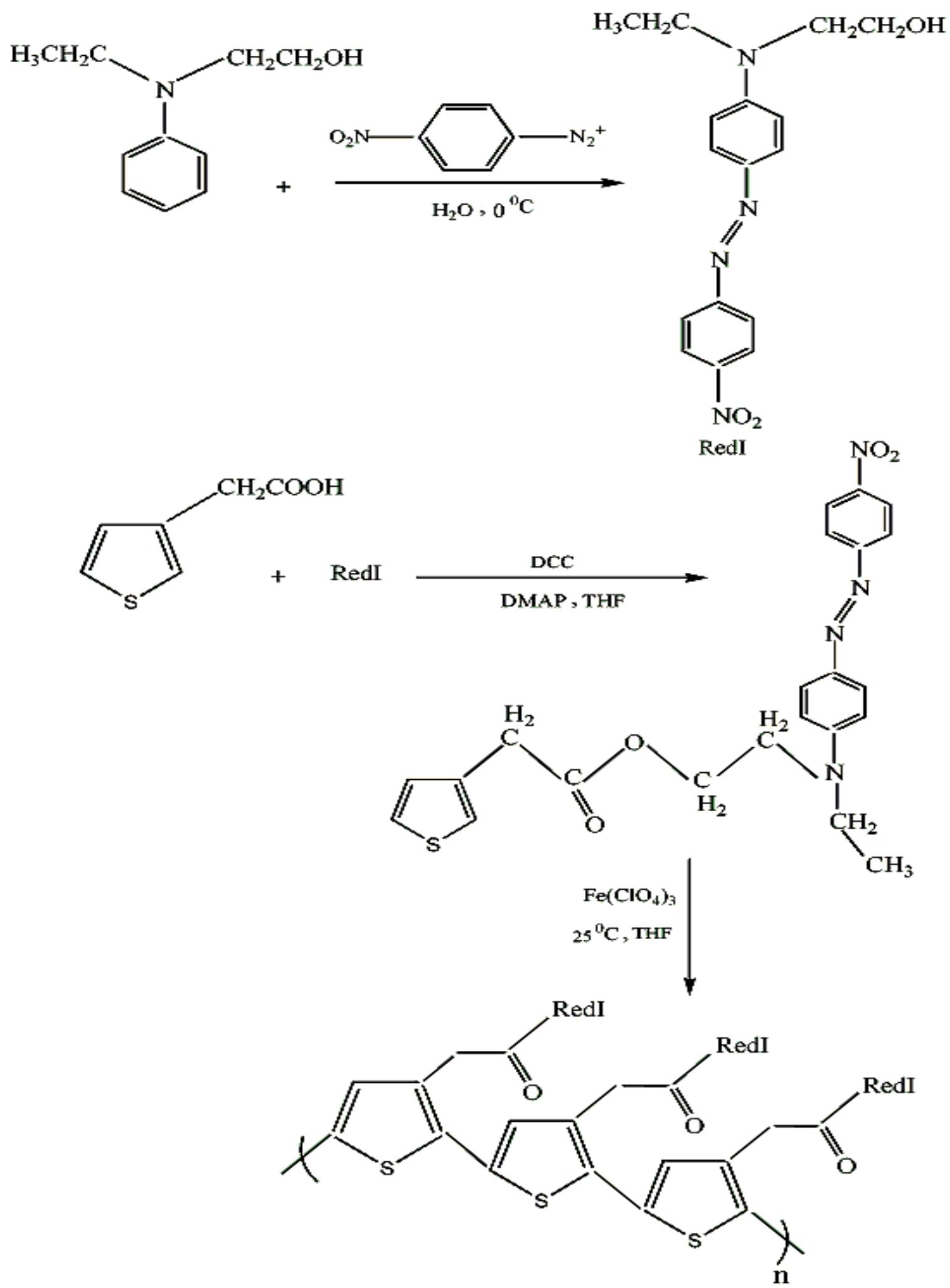

Scheme I: Schematic reactions for route synthesis of poly(Th3AA-RedI) 


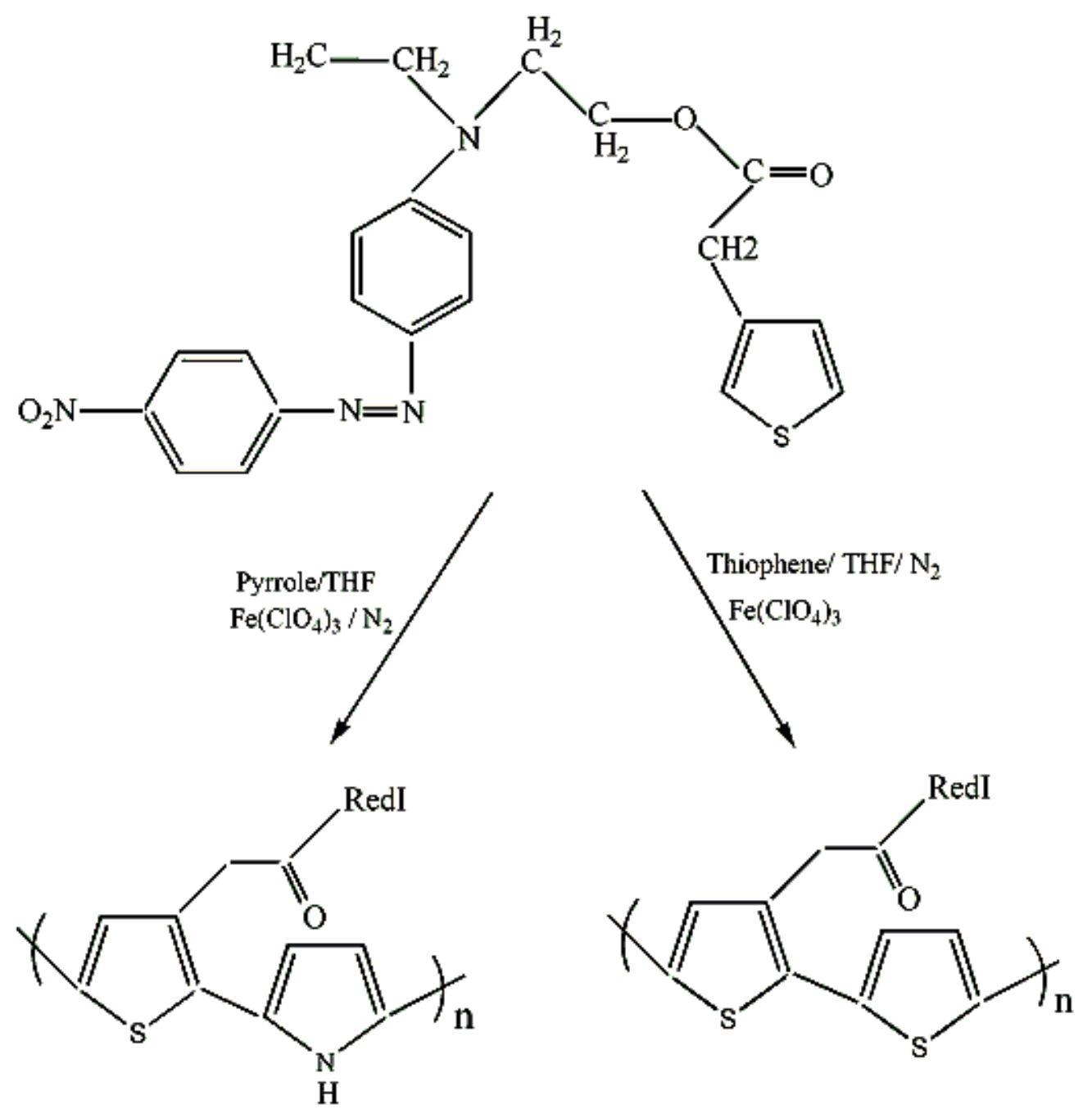

Scheme II: Schematic reactions for copolymerization of poly(Th3AA-RedI) with pyrrole and thiophene 


\subsection{Structural characterization}

In order to obtain polymers with higher molecular weights, the polymerization and copolymerization were carried out at $50{ }^{\circ} \mathrm{C}$ temperature with dropwise addition of monomers. This polymer was found to be soluble in chloroform, THF and methylene chloride, but two copolymers synthesized by chemical oxidative copolymerization using
$\mathrm{FeCl}_{3}$ or $\mathrm{Fe}\left(\mathrm{ClO}_{4}\right)_{3}$ that are not soluble in common organic solvents. Figure 3, illustrates the FT-IR spectra of poly(Th3AA-RedI). The peaks about 3100 and $2910 \mathrm{~cm}^{-1}$ related to $\mathrm{C}-\mathrm{H}$ (aromatic) and C-H (aliphatic) stretching vibrations respectively. The peaks at around $1625 \mathrm{~cm}^{-1}$ and $1140 \mathrm{~cm}^{-1}$ are due to the carbonyl $(\mathrm{C}=\mathrm{O})$ stretching vibration and $\mathrm{C}-\mathrm{O}$ $\mathrm{C}$ Stretching vibration respectively.

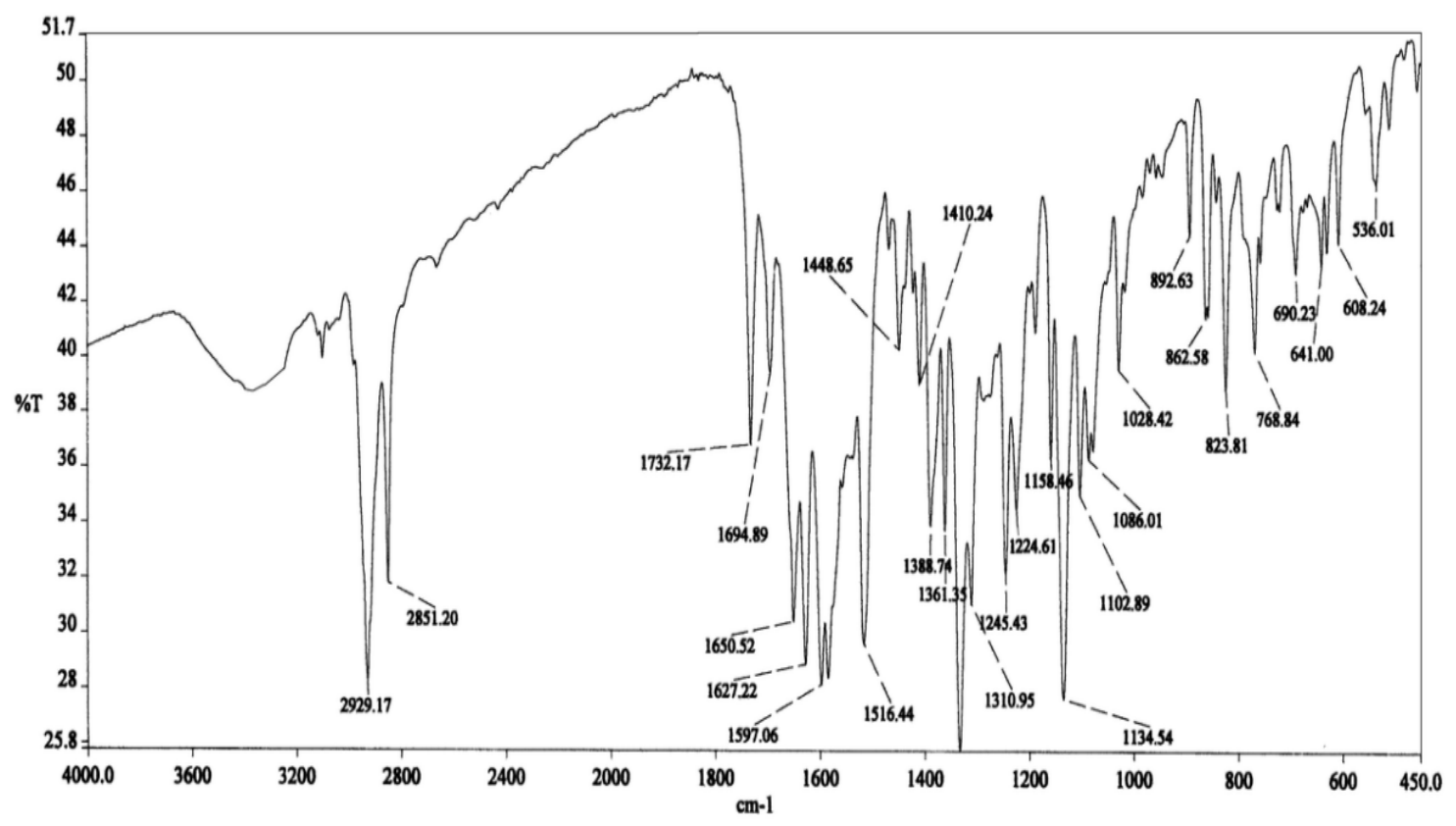

Figure 3: FT-IR Spectrum of poly(Th3AA-RedI)

Figure 4 shows the ${ }^{1} \mathrm{H}-\mathrm{NMR}$ spectrum of poly(Th3AA-RedI). On the basis of comparing with the spectrum of monomer, we can assign the following peaks for poly(Th3AA-RedI): $1.24\left(-\mathrm{CH}_{3}\right), 3.12$ (DMSO), $3.47\left(-\mathrm{CH}_{2}-\mathrm{CH}_{3}\right)$, $3.66\left(-\mathrm{CH}_{2}-\mathrm{N}\right), 3.79\left(-\mathrm{CH}_{2}-\mathrm{COOH}\right), 4.33$ (-O$\left.\mathrm{CH}_{2-}\right)$, 6.79,7.87-7.93 and 8.3-8.33 ppm (protons of phenylene groups). The lines refer to the aromatic protons of the thiophene ring that are located at 7.01-7.30 ppm. The oxidative polymerization for $\beta$-substituted thiophene monomer with $\mathrm{Fe}\left(\mathrm{ClO}_{4}\right)_{3}$ always leads to two different types of couplings: head-to-tail and head-to-head. Thus, the $\alpha$ methylene protons directly attached to the thiophene ring ( $\beta$-position) and can be incorporated into a polymer chain with the above two diads. The two peaks located at 1.3$1.9 \mathrm{ppm}$ arise from the methylene protons between the ester group and the thiophene ring, showing that poly(Th3AA-RedI) has a stereo random chain structure with almost equal distribution of head-to-tail and head-tohead linkages along the polymer chain. 
틍
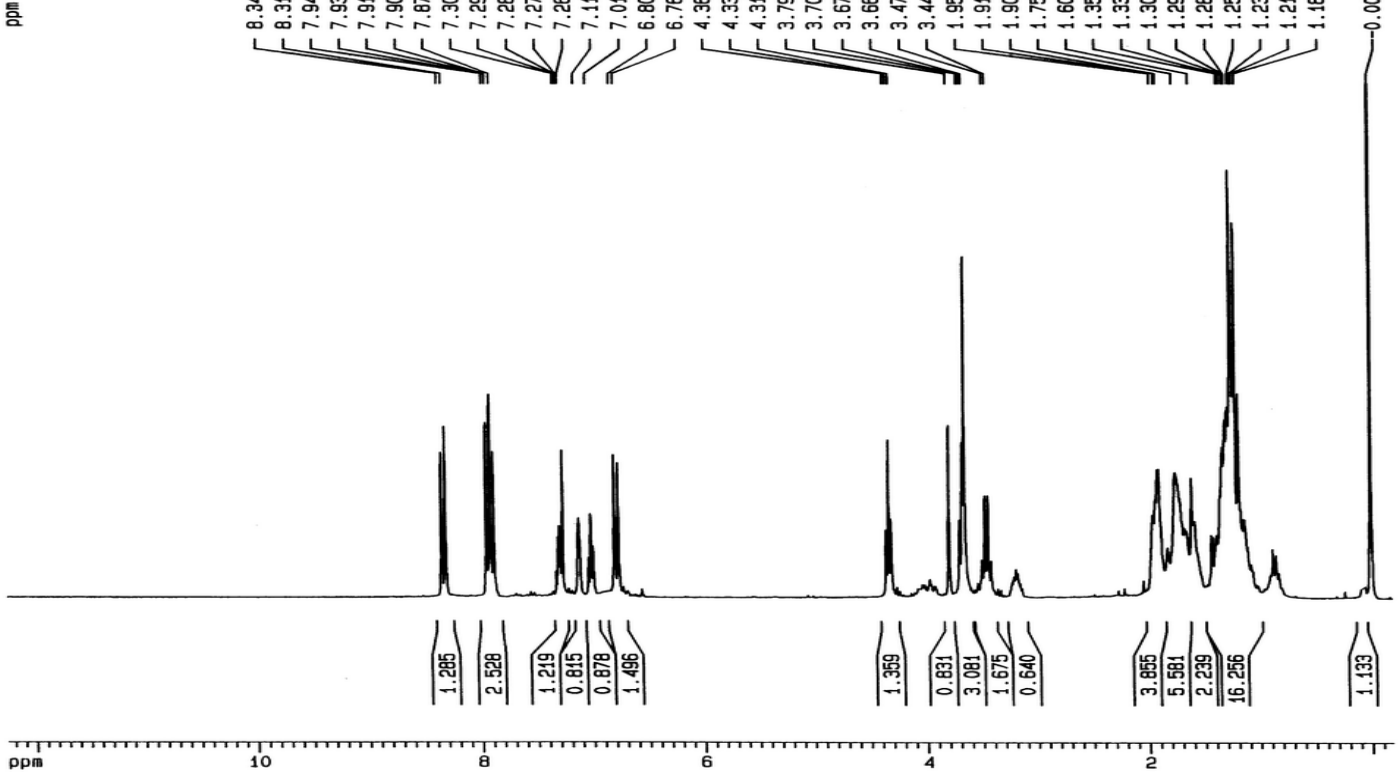

Figure 4: $\mathrm{FT}^{1} \mathrm{H}-\mathrm{NMR}$ Spectrum of poly(Th3AA-RedI)

The ${ }^{13} \mathrm{C}-\mathrm{NMR}$ spectrum of the poly(Th3AARedI) is shown in Figure 5. Using INEPTpulse sequence, we were able to distinguish the proton bonded carbons form all other carbons present in the molecule. On the basis of a comparison with the spectra of poly(Th3AARedI), the following assignments are proposed: The line at the lowest filed (171.5ppm) corresponds to the carbon of the ester group. The lines at 156.7, 151, 147.3, 143.8, 126.2,
124.6, 122.6 and $111.4 \mathrm{ppm}$ are assigned to the aromatic carbon in the RedI moiety. The remaining four lines at $123.1,126,128.4 \mathrm{ppm}$ originate from the carbons of the thiophone ring. In the aliphatic part, the lines of low intensity at $12.2,35.7,45.5,48.6$ and $61.8 \mathrm{ppm}$ correspond to the RedI substituent. The peaks located at 76.5-77.5 ppm arise from the ${ }^{6} \mathrm{~d}$ DMSO solvent. 

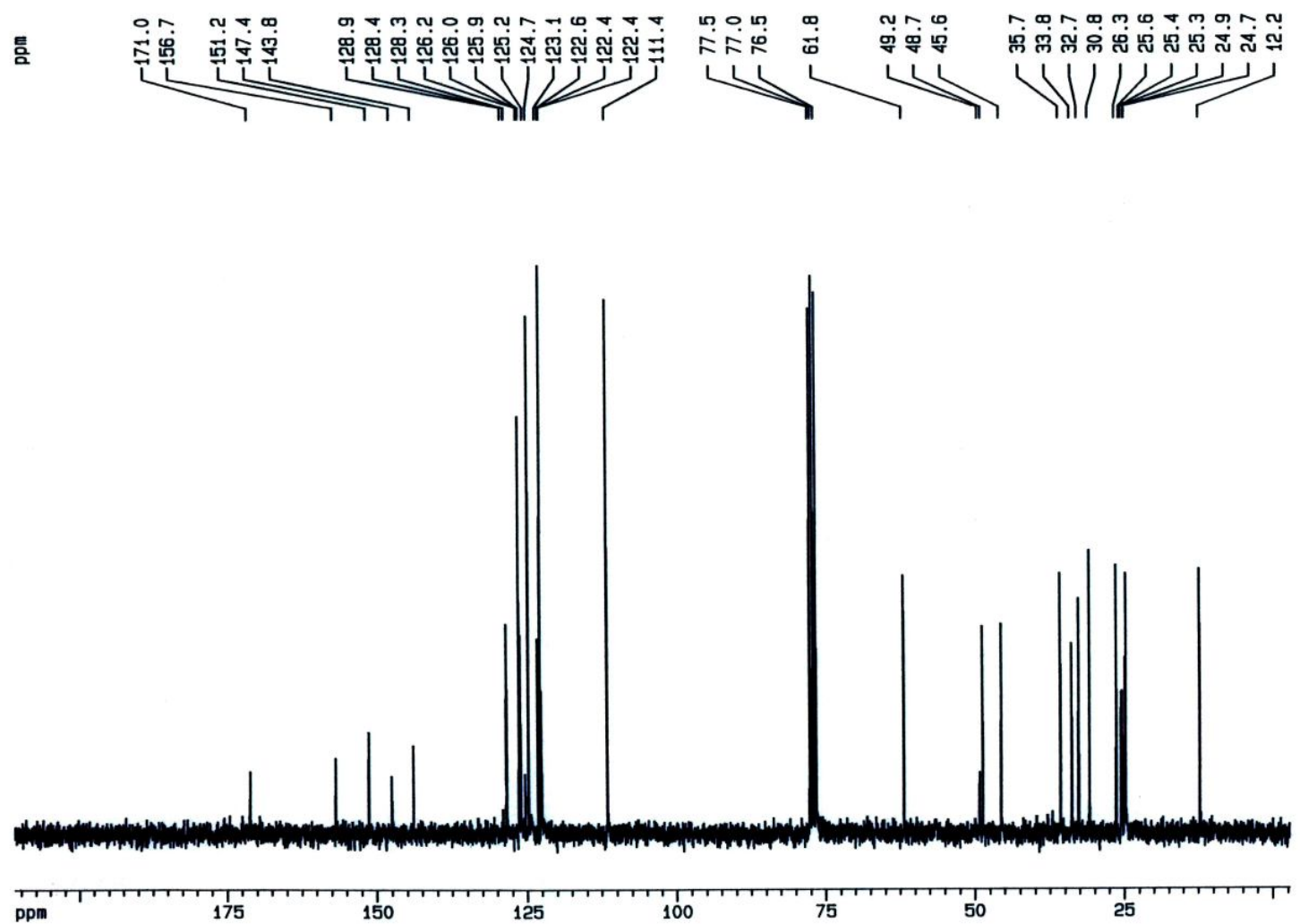

Figure 5: $\mathrm{FT}^{13} \mathrm{C}-\mathrm{NMR}$ Spectrum of poly(Th3AA-RedI)

Figure 6, shows ${ }^{1} \mathrm{H}-\mathrm{NMR}$ spectrum of the copolymer poly(Th3AA-RedI-co-Th) in $\left({ }^{6} \mathrm{~d}-\right.$ DMSO) solvent. In this spectrum, peaks of aliphatic protons $\left(-\mathrm{CH}_{3}\right),\left(\mathrm{CH}_{2} \mathrm{COOH}-\right)$ and ($\mathrm{CH}_{2}-\mathrm{CH}_{3}$ ) observed in 1 to $2.2 \mathrm{ppm}$. Peak of protons $\left(-\mathrm{CH}_{2}-\mathrm{N}\right)$ AND $\left(-\mathrm{O}-\mathrm{CH}_{2}-\right)$ are not observed in spectra, because of overlaping with peak of DMSO and water around 2.21 and $3.3 \mathrm{ppm}$, respectively. Protons of aromatic ring and thiophene are characterized between 6.7 to $8.32 \mathrm{ppm}$. Of course peaks of aromatic area are not clear precisely because they are blocked copolymer, but it is appeared in the area related to aromatic compounds. Copolymer has a low solubility; so ${ }^{1} \mathrm{H}-\mathrm{NMR}$ is not clear. The great adherence from peak is resulted of the greater involvement of thiophene monomers than Th3AA-RedI monomer in polymeric chain. The peaks in aromatic region confirm performance of copolymerization. We were not able to investigate UV-Visible and ${ }^{13} \mathrm{CNMR}$ spectra of poly(Th3AA-RedI-co-Th) and poly(Th3AARedI-co-Py) because of low solubility of them. 


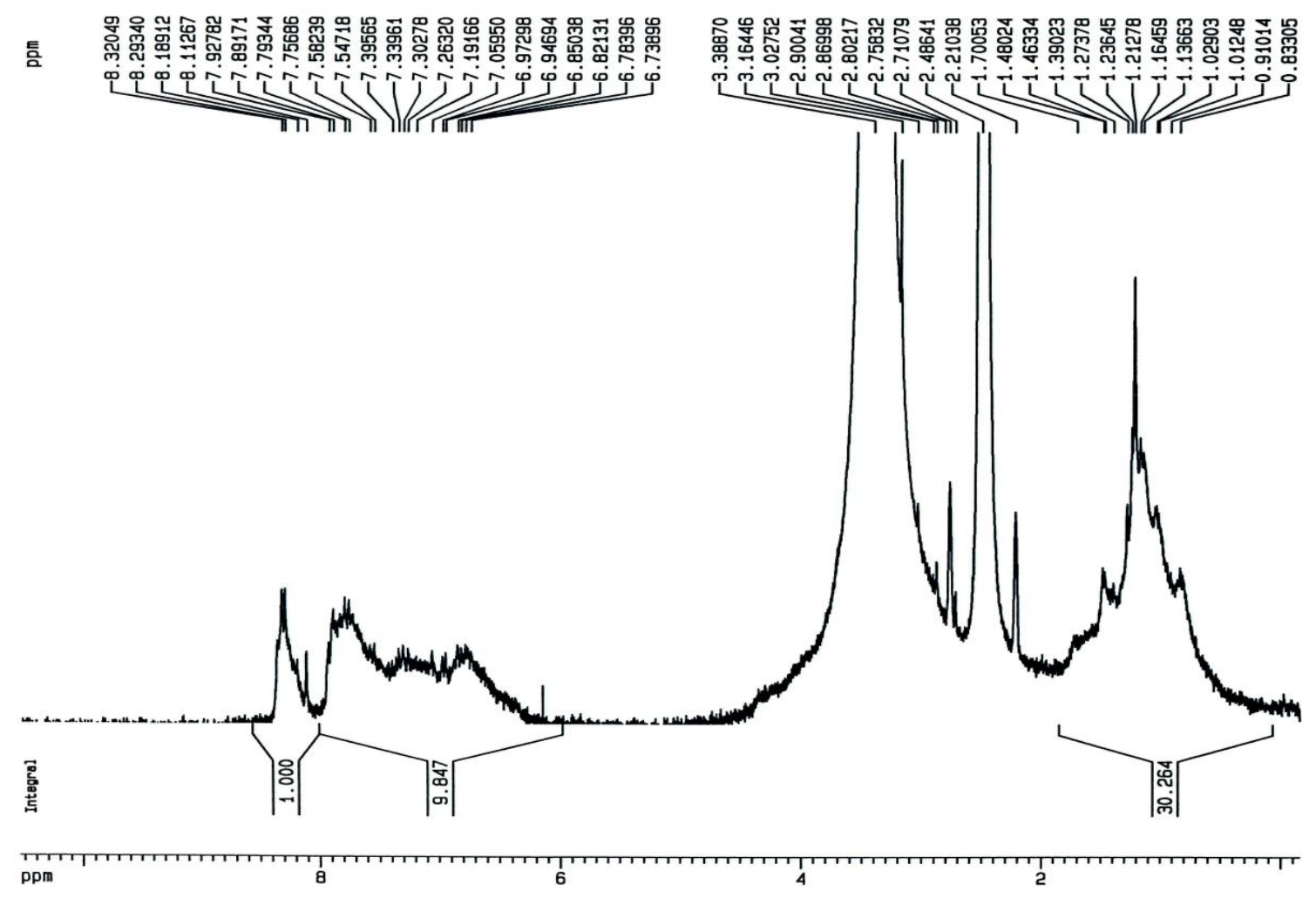

Figure 6: $\mathrm{FT}^{1} \mathrm{H}-\mathrm{NMR}$ Spectrum of poly(Th3AA-RedI-Co-Th)

3.2. Liquid crystalline and thermal properties

Liquid crystallinity and thermal analysis of the polymer were conducted by optical absorption, optical polarizing microscope, differential scanning calorimeter (DSC). Phase transition temperatures were determined by DSC measurement. All DSC runs in this research were made under a nitrogen atmosphere with a heating rate of $5^{0} \mathrm{C} / \mathrm{min}$. DSC thermograms of RedI in heating and cooling process are showed in Figures 7. It shows thermogram an endothermic peak at $173^{\circ} \mathrm{C}$ which is related to the melting process of RedI and also a transformation of crystalline phase to isotropic state. Therefore, crystalline phase of this compound is changed directly to isotropic liquid as a result of temperature effect. In cooling process no peak is observed probably because the sample decomposition occurs at higher temperature or it does not have clear LC behavior. By heating the sample again no peak is observed, this confirms probable sample decomposition. 


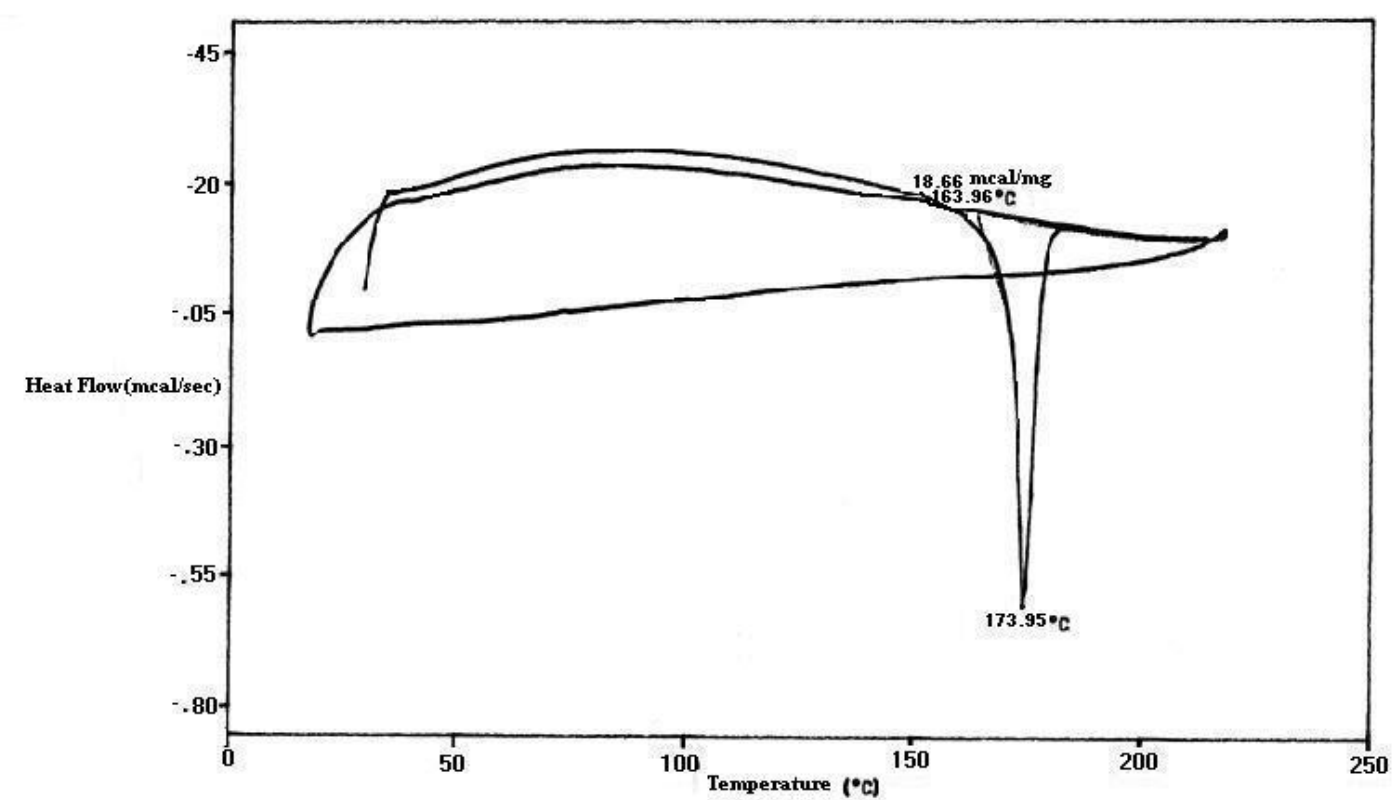

Figure 7: DSC thermogram of RedI, heating and cooling with rate of $5{ }^{\circ} \mathrm{C} / \mathrm{min}$

Transition temperatures for (Th3AA-RedI) were obtained using DSC which shows in Figure 8. DSC thermogram of (Th3AA-RedI) showed two endothermic peaks. The first endothermic peak at $112.93{ }^{\circ} \mathrm{C}$ is an indication of changing of crystalline phase to smectic $\mathrm{C}$ liquid crystalline state $\left(\mathrm{C} \rightarrow \mathrm{S}_{\mathrm{C}}\right)$. The second peak at $177.30^{\circ} \mathrm{C}$ is related to the changing of smectic $\mathrm{C}$ liquid crystalline mesophase to isotropic state $\left(\mathrm{S}_{\mathrm{C}} \rightarrow \mathrm{I}\right)$. In the first transition, the stability of liquid crystalline mesophase is about

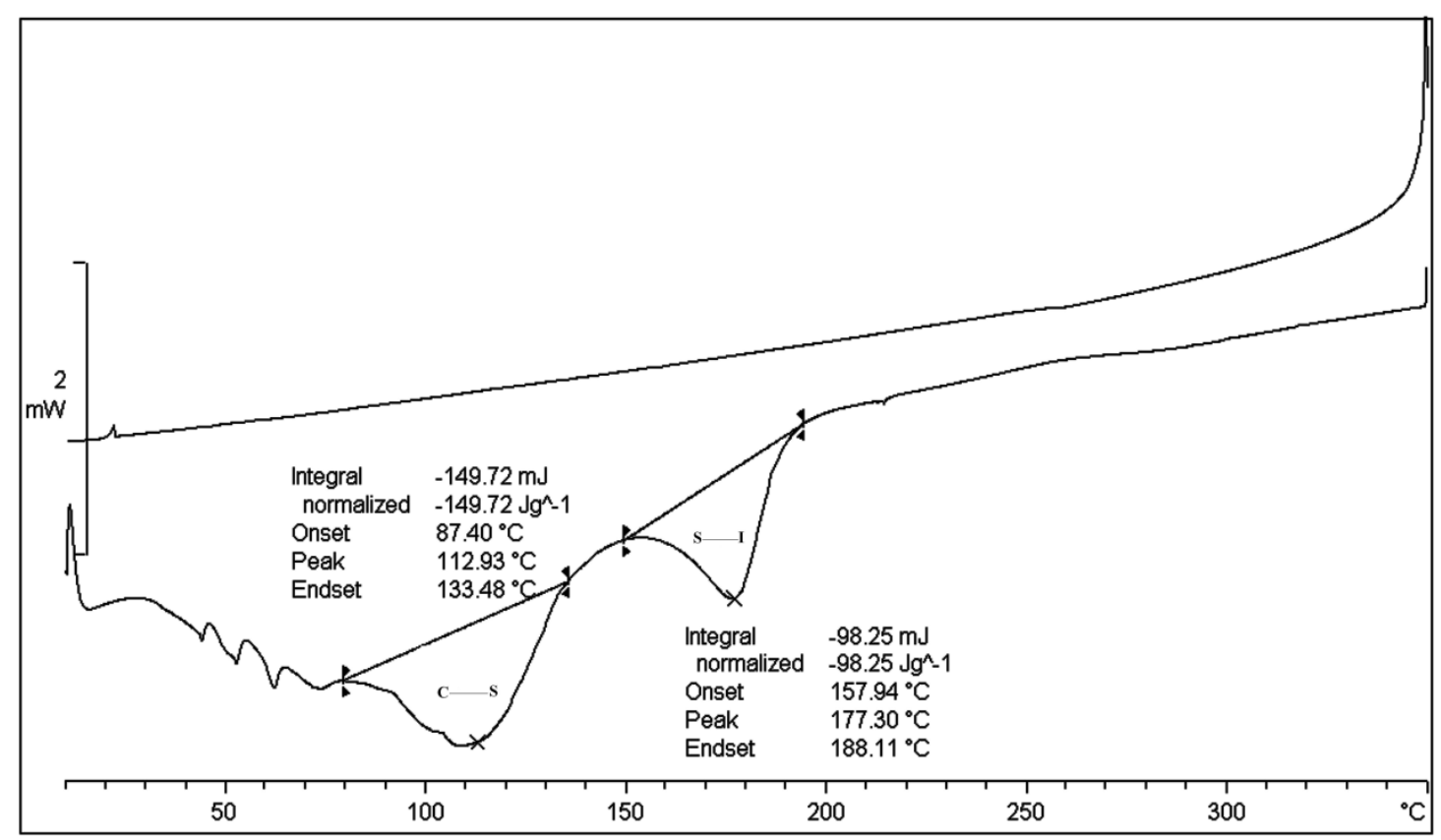

Figure 8: DSC thermogram of (Th3AA-RedI) with rate of $5^{\circ} \mathrm{C} / \mathrm{min}$

The transition temperatures for poly(Th3AARedI) were obtained using DSC which shows in Figure 9. DSC thermogram of poly(Th3AARedI) shows 3 glass transition about 108, 200, $261^{\circ} \mathrm{C}$. The first endothermic peak at $108.15^{\circ} \mathrm{C}$ is an indication of changing of crystalline phase to smectic $\mathrm{C}$ liquid crystalline state $\left(\mathrm{C} \rightarrow \mathrm{S}_{\mathrm{C}}\right)$. The second peak at $200.39^{\circ} \mathrm{C}$ is related to the changing of smectic $\mathrm{C}$ liquid crystalline mesophase to nematic state $\left(\mathrm{S}_{\mathrm{C}} \rightarrow \mathrm{N}\right)$. The last observed endothermic peak in this curve is about $261.29^{\circ} \mathrm{C}$ that is related 
to transition phase of nematic liquid crystalline to isotropic liquid $(\mathrm{N} \rightarrow \mathrm{I})$. In the first and the second transition, the stability liquid crystalline mesophases are about $92.24^{\circ} \mathrm{C}$ and $61^{\circ} \mathrm{C}$ respectively.

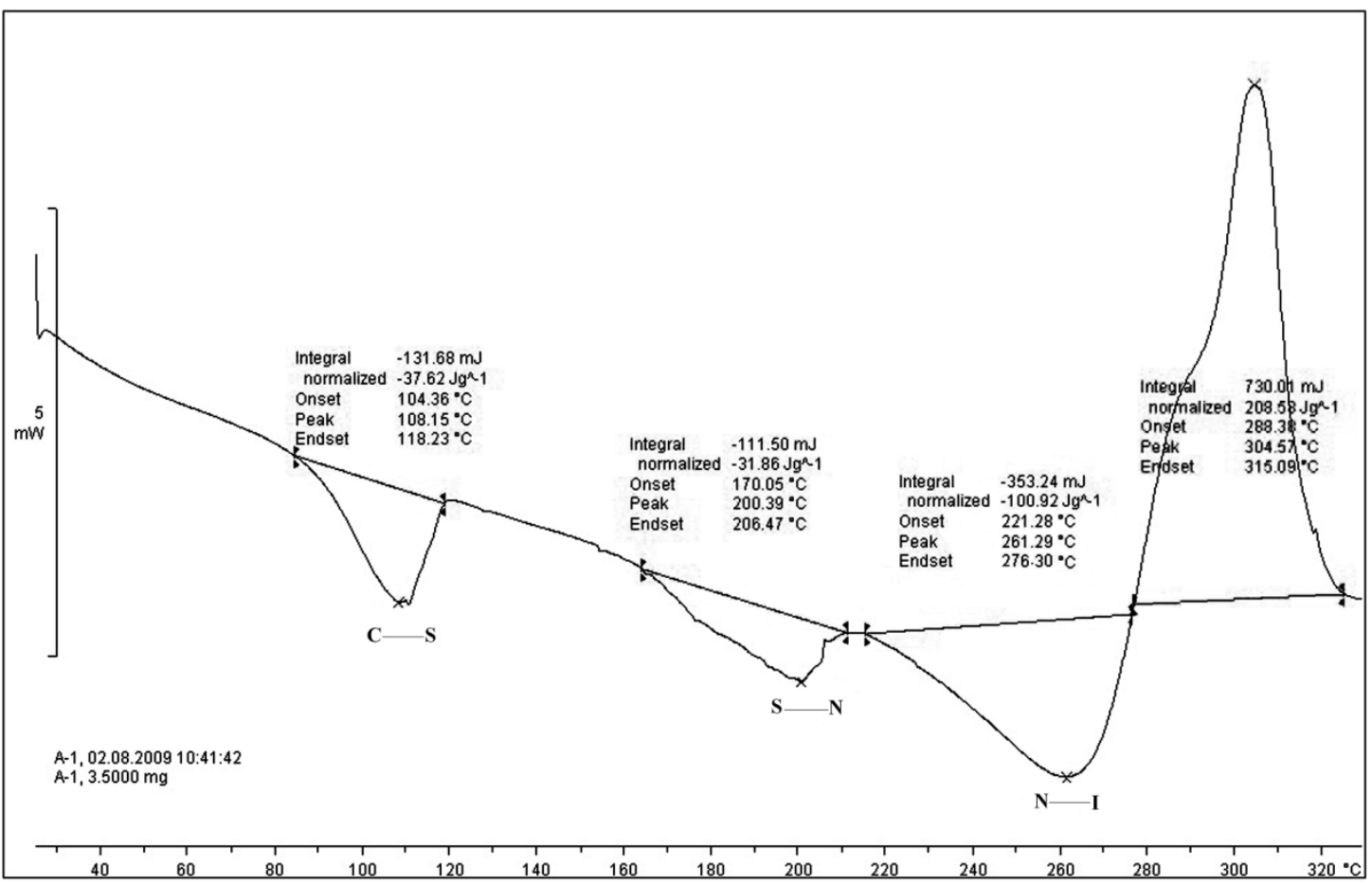

Figure 9: DSC thermogram of poly(Th3 AA-RedI) with rate of $5{ }^{\circ} \mathrm{C} / \mathrm{min}$

The images of polarizing optical microscope of poly(Th3AA-RedI) demonstrate the smectic C, nematic and isotropic liquid crystalline state in the ranges $118^{\circ} \mathrm{C}$ and $206^{\circ} \mathrm{C}$ and $261^{\circ} \mathrm{C}$ temperature respectively. This indicates the
poly(Th3AA-RedI) is a monotropic compound. Typical crystalline, smectic C, nematic texture and isotropic state of poly(Th3AA-RedI) are shown in Figure10(ac). 


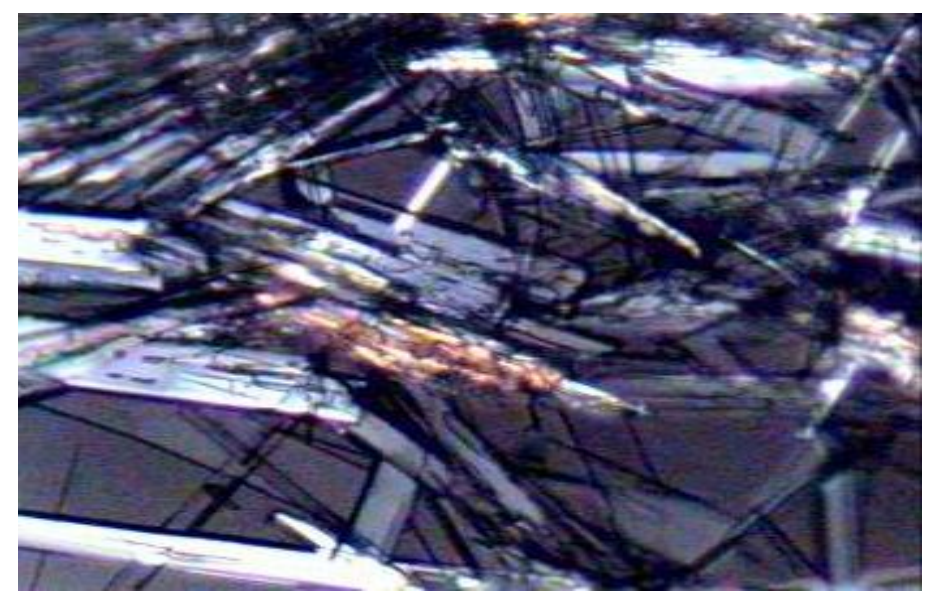

a
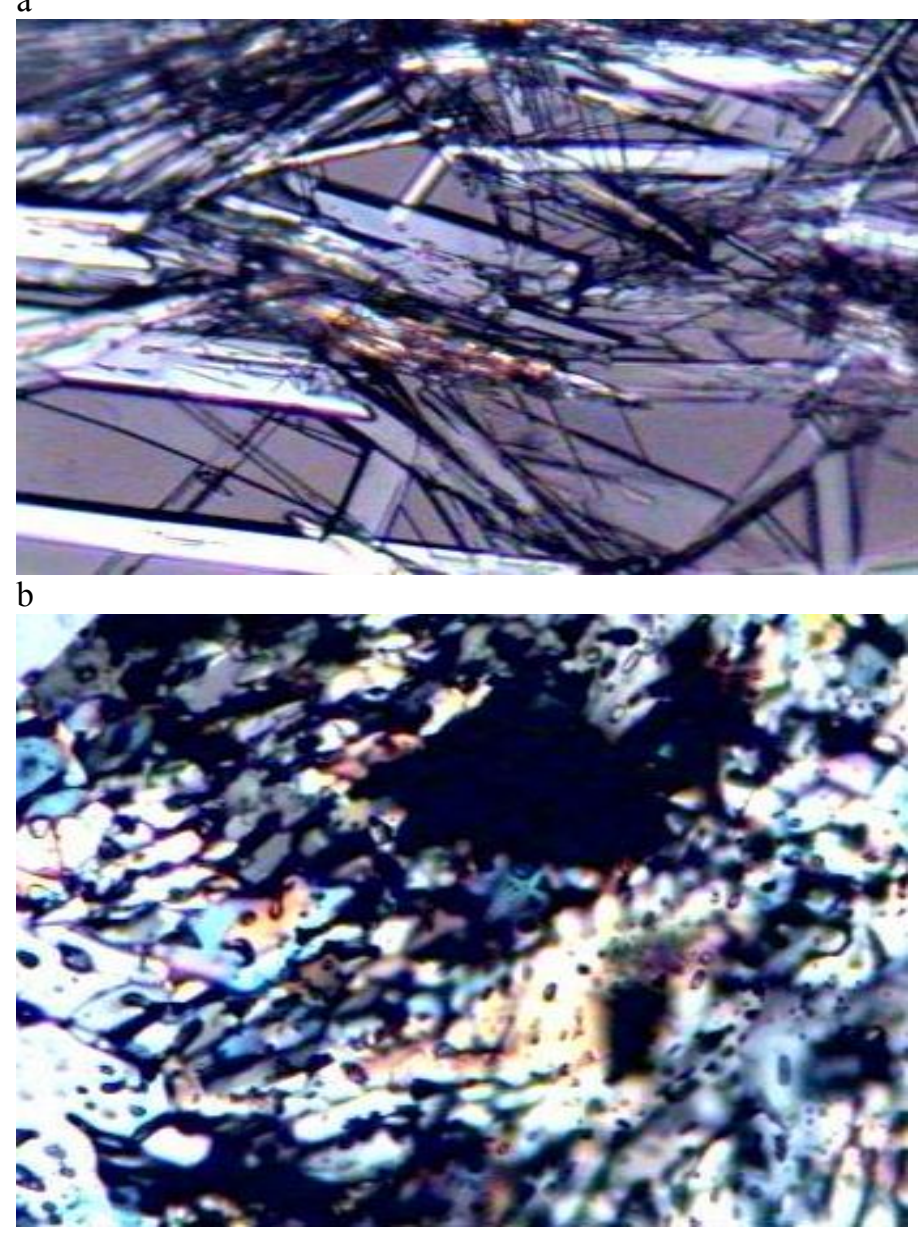

c

Figure 10: Cross-polarized optical micrograph of the polymer sample, smectic $\mathrm{C}$ phases a) $108-170^{\circ} \mathrm{C}$, b) $200-221^{\circ} \mathrm{C}$, c) $261-276^{0} \mathrm{C}$.

\section{Conclusion}

In this paper, we have described the preparation and investigation of liquid crystalline polythiophene with azobenzene group in side chain. The results indicate that this azobenzene functionalized polythiophene derivatives have wide mesophase temperature range and good photoactivity. DSC thermogram of poly(Th3AA-RedI) showed 3 semi glass transition and three endothermic peaks. The endothermic peaks are indicated of changing of $\left(\mathrm{C} \rightarrow \mathrm{S}_{\mathrm{C}}\right),\left(\mathrm{S}_{\mathrm{C}} \rightarrow \mathrm{N}\right)$ and $(\mathrm{N} \rightarrow \mathrm{I})$. The images of polarizing optical microscope of poly(Th3AA-RedI) demonstrated the smectic $\mathrm{C}$, nematic and isotropic liquid crystalline states. Chemical, structural, thermal and morphological studies indicated that high quality polymer film can be obtained. As- 
formed polymer film was thoroughly soluble in polar solvent such as THF.

\section{References}

1. A. Pron, P. Rannou, Processible conjugated polymer: from organic semiconductor to organic metal and superconductors, 27(2002)135-190.

2. I. Osaka, H. Goto, K. Itoh, K. Akagi, Dichroic fluorescence of liquid crystalline polythiophene and polythienylenevinylen derivative, Synthetic Metals 119(2001)541-542.

3. H. Goto, K. Akagi, Syntheses and properties of thiophene and pyrrolebased liquid crystalline small-bandgap conjugated polymers, Synthetic Metals 102(1999)1292.

4. S. H. Jin, H. J. Lee, Y. K. Sun, H. D. Kim, K. N. Koh, Y. S. Gal, Synthesis and characterization of side chain liquid crystalline polymer with a polythiophene backbone, European Polymer Journal 35(1999)89-94.

5. H. Goto, M. Okuda, T. Oohazama, K. Akagi, Liquid crystalline polyaniline derivatives, Synthetic Metals 102(1999)1293-1294.

6. X. Zaho, M. Wang, Synthesis and photoresponsive behavior of azobenzene-functionalized polythiophene film, European Polymer Journal 42(2006)247-253.

7. X. M. Dai, H. Narihiro, H. Goto, k. Akagi, H. Yokoyama, Ferroelectric liquid crystalline polythiophene derivatives, Synthetic Metals 119(2001)397-398.

8. S. H. Hosseini, A. A. Entezami, Chemical and electrochemical synthesis of polymer and copolymers of 3-metohoxythiophene with anline, thiophene, pyrrole and studies of their gas and vapor sensing, Polymers for Advanced

Technologes, 12(2001)524-534.

9. H. Goto, K. Itoh, K. Akagi, Orientational behavior of monosubstituted liquid crystalline polyaniline derivative, Synthetic Metals 119(2001)351-352.

10. X. Zaho, X. Hu,P. J. Zheng, L. H. Gan, C. K. Lee, Synthesis and characterization azobenzene as side chain, Thin Solid Films, 477(2005)88-94.

11. X. M. Dai, H. Goto, K. Akagi, H. Shirakawa, Synthesis and properties of polythiophene derivatives with ferroelectric liquid crystalline substituent, Synthetic Metals 102(1999)1291.

12. I. Osaka, S. Shibata, R. Toyoshima, K. Akagi, and H. Shirakawa Synthesis and properties of liquid crystalline polythiophene derivatives, Synthetic Metals 102(1999)1437-1438.

13. S. H. Hosseini, M. Mohammadi, Preparation and characterization of new poly-pyrrole having side chain liquid crystalline moieties, Materials Science \& Engineering 29(2009)1503-1509. 